\title{
One Continuous Data Fault Diagnosis Method Based on Rough Set Theory and Fuzzy C-Mean Cluster
}

\author{
Guangyi Zhang ${ }^{1}$, Libin Yang ${ }^{2}$ and Yanqin Su, \\ ${ }^{1}$ Department of Science Research, Naval Aeronautical and Astronautical University, Yantai Shandong, China \\ ${ }^{2}$ Department of weapon science and engineering, Naval Aeronautical and Astronautical University, Yantai Shandong, China \\ ${ }^{3}$ Department of Control Engineering, Naval Aeronautical and Astronautical University, Yantai Shandong, China \\ *Corresponding author
}

\begin{abstract}
There is the problem that Rough Set Theory cannot process the quantitative data in the equipment test data. One FCM method is given to discretize the quantitative data, and the center value of the each cluster is calculated in order to discretize. And then, the attribution reduction algorithm and rules extract methods are applied to get the last diagnosis rule, which is applied to some aero radio equipment fault diagnosis to verify its validity.
\end{abstract}

Keywords-fuzzy c-mean cluster; rough set theory; continuous data; diagnosis

\section{INTRODUCTION}

With the development of electronic technology, electronic equipment has more and more proportion in the aviation equipment and their fault diagnosis become the urgent topic [1] In fact, the aviation electronic equipment test data based on ATS/ATE(Auto Test System/Equipment) has obtain plenty of test data, in which there are some continuous data and discretized data. These data often has inaccuracy, redundancy, and Rough Set Theory proposed by Pawlak has some advantage to process these data [2]. But, RST just can process the discretized data, so it is need to discretize the continuous data firstly. Meanwhile, the fault mode of the test data is often fuzzy. Here, one fusion method based on Rough Set Theory and Fuzzy Set Theory is studied, and the fuzzy clustering method is used to discretize because it can divide the different subsets [3].

The paper chooses Fuzzy C-mean cluster (FCM)method to discretize, and then Rough Set Theory is applied to reduce the attribution and extract rules in order to get the diagnosis rules. The real example is applied to verify the fusion method.

\section{ROUGH SET THEORY}

\section{A. Basic conception of RST}

In 1982, Polish mathematician Z. Pawlak proposes Rough Sets Theory, and it can be described as bellows:

In rough sets theory, the quad system $S=(U, A, V, f)$ is a knowledge representation system (decision table), in which $U$ is the domain, $A$ is attribute set, $V=\bigcup_{\alpha \in A} V_{\alpha}$, and $V_{\alpha}$ is the range of the property $\alpha . f: U \times A \rightarrow V$ is an information function, it gives each attribute of each object an information value, that is, $\forall \alpha \in A, x \in U, f(x, \alpha) \in V_{\alpha}$.

If $A=C \bigcup D, C \cap D=\Phi, C$ is the condition attribute value and $D$ is the decision attribute value, then the knowledge representation system $S$ is called the decision table[2-3].

In which, if there are at least one attribution $\alpha \in C, x \in U, f(x, \alpha) \in V_{\alpha}$ is unknown, and $V_{\alpha}$ has empty value, it is marked by “*”, which is named incomplete fault diagnosis decision table, otherwise it is named complete table.

In 1991, A.Skowron proposes discernibility matrix to express knowledge firstly, and the discernibility matrix is $M_{n \times n}=\left(c_{i j}\right)_{n \times n}$

$$
c_{i j}=\left\{\begin{array}{c}
\left\{\alpha \mid(\alpha \in A) \wedge\left(f_{\alpha}\left(x_{i}\right) \neq f_{\alpha}\left(x_{j}\right)\right)\right\}, f_{D}\left(x_{i}\right) \neq f_{D}\left(x_{j}\right) \\
\Phi, \quad f_{D}\left(x_{i}\right) \neq f_{D}\left(x_{j}\right) \wedge f_{C}\left(x_{i}\right)=f_{C}\left(x_{j}\right) \\
-, \quad f_{D}\left(x_{i}\right)=f_{D}\left(x_{j}\right) \\
\forall i, j=1,2, \cdots, n
\end{array}\right.
$$

In $S=(U, A, V, f)$, the core $M_{n \times n}$ is defined that all single attribution set, that is $C O \operatorname{COR}_{C}(D)=\left\{\alpha \mid(\alpha \in C) \wedge\left(\exists c_{i j},\left(\left(c_{i j} \in M_{n \times n}\right) \wedge\left(c_{i j}=\{\alpha\}\right)\right)\right)\right\}$

Then, the relative discernibility matrix defines as

$$
\begin{gathered}
M^{R}=\left(M_{i j}^{R}\right)_{n \times n}= \begin{cases}0, & c_{i j}=\operatorname{CORE}_{C}(D) \\
c_{i j}, & \text { the others }\end{cases} \\
\forall i, j=1,2, \cdots n
\end{gathered}
$$

Here, assume the divisions of the decision attribute $D$ in the domain $U$ is $D: D=\left\{D_{1}, D_{2}, \cdots D_{m}\right\}$, and define condition information entropy of condition attribute $C$ relative to the decision attribute $\mathrm{D}$ is[4] 


$$
\begin{aligned}
& H(D \mid C)=-\sum_{i=1}^{n} P\left(C_{i}\right) \sum_{j=1}^{m} P\left(D_{j} \mid C_{i}\right) \log P\left(D_{j} \mid C_{i}\right) \\
& =-\sum_{i=1}^{n} \sum_{j=1}^{m} P\left(C_{i} \mid D_{j}\right) \log P\left(D_{j} \mid C_{i}\right)
\end{aligned}
$$

In which, $P\left(C_{i}\right)$ is the probability of condition attributes $C_{i}, P\left(D_{j} \mid C_{i}\right)$ and $P\left(C_{i} \mid D_{j}\right)$ are condition probability respectively.

\section{B. The Condition Entropy Attribution Reduction Algorithm}

The algorithm steps are as bellows [5]:

Step1 Calculate discernibility matrix $M$ and relative core $C O R E_{D}(C)$, and order $R E D=\operatorname{CORE}_{D}(C)$;

Step2 Set up all the elements that contain $R E D$, the relative discernibility matrix $M^{R}$ is got, if $M^{R}=0$, then the algorithm end, or jump to Step3;

Step3 Order the attribution set Att of nonzero element $M^{R}$, for every attribution $\alpha_{i} \in A t t$, calculate $H\left(D \mid R E D \bigcup\left\{\alpha_{i}\right\}\right)$;

Step4 Choose the attribution $\alpha_{j}$ of minimum $H\left(D \mid R E D \cup\left\{\alpha_{i}\right\}\right)$. If there are multiple minimum attributes, the attribute which emerge more times in the discernibility matrix is selected. Order Att $=A t t-\left\{\alpha_{j}\right\}, R E D=R E D \bigcup\left\{\alpha_{j}\right\}$.

Step5 According to the new $R E D$, calculate the relative discernibility matrix $M^{R}$, if $M^{R}=0$, then the algorithm end, or jump to Step3.

Then, according to the intersection set and union set principle, the last diagnosis rules are got.

\section{FCM CLUSTER BASED ON EXTREME DIFFERENCE SPECIFICATION}

Order there are $\mathrm{n}$ sample needed to classify in the original fault example data $U$ of ATS/ATE, and they have m character index, and the data matrix is established as[6]:

$$
U=\left[\begin{array}{lllc}
u_{11}^{\prime} & u_{12}^{\prime} & \cdots & u_{1 m}^{\prime} \\
u_{21}^{\prime} & u_{22}^{\prime} & \cdots & u_{2 m}^{\prime} \\
\cdots & \cdots & \cdots & \cdots \\
u_{n 1}^{\prime} & u_{n 2}^{\prime} & \cdots & u_{n m}^{\prime}
\end{array}\right]
$$

The Sample set $D=\left(\left\{d_{1}, d_{2}, \cdots, d_{c}\right\}\right)$ is divided to $2 \leq c \leq n$ categories, and the matrix $V$ is got based on $c$ cluster center vector.

$$
V=\left[\begin{array}{c}
V_{1} \\
V_{2} \\
\cdots \\
V_{C}
\end{array}\right]\left[\begin{array}{cccc}
v_{11} & v_{12} & \cdots & v_{1 m} \\
v_{21} & v_{22} & \cdots & v_{2 m} \\
\cdots & \cdots & \cdots & \cdots \\
v_{C 1} & v_{C 2} & \cdots & v_{C m}
\end{array}\right]
$$

The FCM algorithm minimizes the target function through solving the divided matrix $W$ and cluster center matrix $V$, and the restrain condition of the target function is $\sum_{i=1}^{C} w_{i j}=1,(j=1,2, \cdots, n)$. The optimization problem expression is

$$
J_{m}(U, W, V)=\sum_{j=1}^{n} \sum_{i=1}^{C} w_{i j}^{m}\left\|u_{j}-v_{i}\right\|^{2}
$$

In which, $V=\left\{v_{1}, v_{2}, \cdots, v_{C}\right\}$ is the fuzzy cluster center, $\left\|u_{j}-v_{i}\right\|^{2}$ is cluster center distance between the sample $u_{j}$ and $v_{i}, m(1 \leq m \leq \infty)$ is the fuzzy factor. So, the optimization problem can be got by the below two formula iteration.

$$
v_{i}=\frac{\sum_{j=1}^{n}\left(w_{i j}\right)^{m} u_{j}}{\sum_{j=1}^{n}\left(w_{i j}\right)^{m}}, 1 \leq i \leq C
$$

$$
w_{i j}=\left[\sum_{k=1}^{c}\left(\frac{\left\|u_{j}-v_{i}\right\|^{2}}{\left\|u_{j}-v_{k}\right\|^{2}}\right)^{\frac{1}{m=1}}\right]^{-1}, 1 \leq i \leq C, 1 \leq j \leq n
$$

The algorithm steps are as bellows:

Step1: Calculate the original cluster center $v_{1}^{(0)}, v_{2}^{(0)}, \cdots, v_{C}^{(0)}$ based on the test data;

Step2: The extreme difference specification method is applied to get the similar relationship between the samples and the $C$ categories center;

Step3: The original divided matrix is got by $\gamma_{i j}^{\prime}$;

Step4: Update the fuzzy divide matrix;

Step5: If the target function achieves the threshold $\varepsilon$ or maximum iteration times $N$, the iteration ends, or jump to 
Step 2. Lastly, $C$ cluster center and subordinate degree divide matrix $W^{\prime}$ is got.

\section{APPLICATION MODEL AND EXAMPLE ANALYSIS}

Some aviation radio equipment is classical aviation electronic equipment, so it is chosen to be fault diagnosed of the above method. Table I gives the fault phenomenon of "the radio station is uncontrolled", in which the fault omen is expressed as condition attribution " $C$ ", $C=\{+5 \mathrm{~V}$ voltage $C_{1}$,UUT receiver voltage $C_{2}$, UUT receiver power $C_{3}$,UUT transmitter voltage $C_{4}$, UUT transmitter power $C_{5}$, 1553B bus $\left.C_{6}\right\}$, decision attribution $D=\left\{d_{1}, d_{2}\right\}$, “ $d_{1}$ ”means fault frontpanel , “ $d_{2}$ ” means fault host PC.

\section{TABLE I. ORIGINAL TEST DATA}

\begin{tabular}{|c|c|c|c|c|c|c|c|}
\hline No & $\boldsymbol{C}_{1}$ & $\boldsymbol{C}_{\mathbf{2}}$ & $\boldsymbol{C}_{\mathbf{3}}$ & $\boldsymbol{C}_{\mathbf{4}}$ & $\boldsymbol{C}_{\mathbf{5}}$ & $\boldsymbol{C}_{\mathbf{6}}$ & $\boldsymbol{D}$ \\
\hline$(1)$ & 5.95 & 28.5 & 30 & 27.17 & 120 & 75 & $\boldsymbol{d}_{1}$ \\
\hline$(2)$ & 5.25 & 27.3 & 35 & 26.6 & 180 & 85 & $d_{1}$ \\
\hline$(3)$ & 6.1 & 29.5 & 75 & 29.5 & 60 & 100 & $d_{1}$ \\
\hline$(4)$ & 4.9 & 28.0 & 55 & 27.3 & 140 & 90 & $d_{2}$ \\
\hline$(5)$ & 5.4 & 27.5 & 25 & 26.4 & 160 & 103 & $d_{2}$ \\
\hline$(6)$ & 5.9 & 22.0 & 27 & 23.7 & 70 & 55 & $d_{2}$ \\
\hline
\end{tabular}

In fact, according to equipment instruction book, the condition attribution work range is given, and the cluster number is chosen to 3 as " $\mathrm{H}$ (higher than the normal value)", "N (normal)" and "L (lower than the normal value)" respectively. The 3 cluster center and their subordinate degree are calculated, and the original test data can be discretized as Table II.

TABLE II. THE DISCRETIZED DATA

\begin{tabular}{|c|c|c|c|c|c|c|c|}
\hline No. & $\boldsymbol{C}_{\mathbf{1}}$ & $\boldsymbol{C}_{\mathbf{2}}$ & $\boldsymbol{C}_{\mathbf{3}}$ & $\boldsymbol{C}_{\mathbf{4}}$ & $\boldsymbol{C}_{5}$ & $\boldsymbol{C}_{\mathbf{6}}$ & $\boldsymbol{D}$ \\
\hline$(1)$ & $\mathrm{H}$ & $\mathrm{N}$ & $\mathrm{N}$ & $\mathrm{N}$ & $\mathrm{H}$ & $\mathrm{N}$ & $d_{1}$ \\
\hline$(2)$ & $\mathrm{L}$ & $\mathrm{N}$ & $\mathrm{N}$ & $\mathrm{N}$ & $\mathrm{H}$ & $\mathrm{N}$ & $d_{1}$ \\
\hline$(3)$ & $\mathrm{H}$ & $\mathrm{H}$ & $\mathrm{H}$ & $\mathrm{H}$ & $\mathrm{L}$ & $\mathrm{H}$ & $d_{1}$ \\
\hline$(4)$ & $\mathrm{L}$ & $\mathrm{H}$ & $\mathrm{N}$ & $\mathrm{N}$ & $\mathrm{H}$ & $\mathrm{N}$ & $d_{2}$ \\
\hline$(5)$ & $\mathrm{L}$ & $\mathrm{N}$ & $\mathrm{N}$ & $\mathrm{L}$ & $\mathrm{H}$ & $\mathrm{H}$ & $d_{2}$ \\
\hline$(6)$ & $\mathrm{N}$ & $\mathrm{L}$ & $\mathrm{L}$ & $\mathrm{L}$ & $\mathrm{N}$ & $\mathrm{L}$ & $d_{2}$ \\
\hline
\end{tabular}

Then, the condition attribution reduction algorithm is applied to get $\mathrm{CORE}=\{1,2\} \quad$, in which $H(d \mid\{1,2\} \bigcup\{4\})=H(d \mid\{1,2\} \bigcup\{6\})=0$ are both minimum. The emergence times is counted, and the condition attribution " 4 " and " 6 " times are both 11 , so $\operatorname{RED}=\{1,2,4,6\}$, and then the attribution value reduction algorithm and rules extraction are applied to get the diagnosis rules as Table III.
TABLE III. DIAGNOSIS RULES

\begin{tabular}{|c|c|}
\hline$C($ Condition attribution) & $\begin{array}{c}D \text { (Decision } \\
\text { attribution) }\end{array}$ \\
\hline $\begin{array}{c}+5 \mathrm{~V} \text { voltage }(\mathrm{H}) \cup \mathrm{UUT} \text { receiver voltage }(\mathrm{N}) \cup \mathrm{UUT} \\
\text { transmitter voltage }(\mathrm{N}) \cup 1553 \mathrm{~B} \text { bus }(\mathrm{N})\end{array}$ & $\begin{array}{l}\text { fault front- } \\
\text { panel }\end{array}$ \\
\hline $\begin{array}{c}+5 \mathrm{~V} \text { voltage }(\mathrm{L}) \cup \mathrm{UUT} \text { receiver voltage }(\mathrm{N}) \cup \mathrm{UUT} \\
\text { transmitter voltage }(\mathrm{N}) \cup 1553 \mathrm{~B} \text { bus }(\mathrm{N})\end{array}$ & $\begin{array}{c}\text { fault front- } \\
\text { panel }\end{array}$ \\
\hline $\begin{array}{c}+5 \mathrm{~V} \text { voltage }(\mathrm{H}) \cup \mathrm{UUT} \text { receiver voltage }(\mathrm{H}) \cup \mathrm{UUT} \\
\text { transmitter voltage }(\mathrm{H}) \cup 1553 \mathrm{~B} \text { bus }(\mathrm{H})\end{array}$ & $\begin{array}{c}\text { fault front- } \\
\text { panel }\end{array}$ \\
\hline $\begin{array}{l}+5 \mathrm{~V} \text { voltage }(\mathrm{L}) \cup \mathrm{UUT} \text { receiver voltage }(\mathrm{H}) \\
\cup \mathrm{UUT} \text { transmitter voltage }(\mathrm{N}) \cup 1553 \mathrm{~B} \text { bus }(\mathrm{N})\end{array}$ & fault host PC \\
\hline $\begin{array}{c}+5 \mathrm{~V} \text { voltage }(\mathrm{L}) \cup \mathrm{UUT} \text { receiver voltage }(\mathrm{N}) \cup \mathrm{UUT} \\
\text { transmitter voltage }(\mathrm{L}) \cup 1553 \mathrm{~B} \text { bus }(\mathrm{H})\end{array}$ & fault host PC \\
\hline $\begin{array}{c}+5 \mathrm{~V} \text { voltage }(\mathrm{N}) \cup \mathrm{UUT} \text { receiver voltage }(\mathrm{L}) \cup \mathrm{UUT} \\
\text { transmitter voltage }(\mathrm{L}) \cup 1553 \mathrm{~B} \text { bus }(\mathrm{L})\end{array}$ & fault host PC \\
\hline
\end{tabular}

\section{CONCLUSION}

FCM cluster method is analyzed and applied to discretize the continuous fault data, and the diagnosis rules is got after the attribution reduction and rule extraction method. It provides a new way to the uncertain equipment fault diagnosis.

\section{REFERENCES}

[1] Zhang Fengming, Hui Xiaobin. Aviation equipment fault diagnostics[M].Beijing: National Defense Industry Press, 2010.(in Chinese)

[2] Liang Jiye,Li Deyu. Information M easures of Roughness of Knowledge and Significance of Attribute in Rough Set Theory[J]. Journal of Engineering Mathematics, 2000,5(17):106-109.

[3] PEDRYCZ W. Algorithms of fuzzy clustering with partial supervision [J].Pattern Recognition Letters, 1985, 3(1): 13-20.

[4] Z. Pawlak. Rough sets[J]. International Journal of Information and Computer Science,1982,11: 365-468

[5] ZHANG Guangyi, SU Yanqin, CHENG Jihong.Approach for fault diagnosis of discernibility matrix and condition entropy fusion. Computer Engineering and Applications,2011,47(17):4-6. (in Chinese)

[6] L. A. Zadeh. Fuzzy sets as a basis for a theory of possibility[J]. Fuzzy Sets and Systems, 1999, 100(supp.):9-34. 